\title{
Adult-Type Glycine Receptors Form Clusters on Embryonic Rat Spinal Cord Neurons Developing in vitro
}

\author{
Paul A. St. John and Sherry L. Stephens \\ Department of Anatomy, Graduate Program in Neuroscience, University of Arizona College of Medicine, Tucson, Arizona \\ 85724
}

The time course of development and the cellular and subcellular distributions of adult-type, strychnine-binding glycine receptors (GlyRs) were examined on rat spinal cord neurons in vitro using both the GlyR antagonist strychnine and a specific antibody against the receptor. Spinal cord neurons in vivo had no detectable adult-type GlyRs at embryonic day 14, the age used to establish cell cultures. After being placed in culture, neurons continued for several days to show no expression of adult-type GlyRs. This contrasted with the observation that these neurons began to express receptors for substance $P$ within $24 \mathrm{hr}$ in culture. Beginning after 5-7 $d$ in culture, however, neurons began to express adult-type GlyRs on their surfaces, and the number of such receptors increased abruptly thereafter. Ultimately, about $80 \%$ of the neurons in heterogeneous spinal cord cultures came to express adult-type GlyRs, with all of them beginning to express the GlyRs at approximately the same time.

The subcellular distribution of adult-type GlyRs on neurons was observed by fluorescence microscopy using both antiGlyR antibody and a fluorescent derivative of strychnine. On neurons that had been in culture for more than $10 \mathrm{~d}$, GlyRs were localized in focal clusters, or aggregates, that were distributed over both cell bodies and neurites. The apparent location of these clusters on the cell surface was confirmed by the observation that GlyRs could be labeled with the antibody on living neurons. The nonuniform distribution of GlyRs was observed using the monovalent probe fluorescent strychnine on living neurons and using the antibody on fixed neurons and on living neurons at $4^{\circ} \mathrm{C}$, thus showing that aggregation of GlyRs was not induced by the labeling procedures. Focal clusters of GlyRs were also seen on younger neurons that were in the early stages of expression of adulttype GlyRs. In addition to the clusters, however, such neurons showed regions where the GlyRs were more diffuse. These results show that adult-type GlyRs are expressed on developing spinal cord neurons only after several days in culture, and that such GlyRs typically form focal clusters on the surfaces of spinal cord neurons, even at very early stages

\footnotetext{
Received Aug. 27, 1992; revised Nov. 9, 1992; accepted Dec. 1, 1992.

This work was supported by awards to P.A.St.J. from the National Science Foundation (BNS-8808506), the National Institutes of Health (NS 29657), the Arizona Disease Control Research Commission (1-0-WC-9311), and the University of Arizona Foundation. We thank Elizabeth Caldwell, Judd Rice, and Matt Burtelow for help with some of the Bodipy-strychnine experiments.

Correspondence should be addressed to Paul A. St. John, Department of Anatomy, University of Arizona College of Medicine, 1501 North Campbell Avenue, Tucson, AZ 85724

Copyright (C) 1993 Society for Neuroscience $0270-6474 / 93 / 132749-09 \$ 05.00 / 0$
}

of their expression. The results also suggest, however, that at the earliest stage of expression, at least some of the adulttype GlyRs on these neurons may have a different, more diffuse distribution.

[Key words: glycine receptors, strychnine, spinal cord, development]

The correct localization of receptors for neurotransmitter is crucial for proper intercellular communication at synapses, and so developmental control of receptor distribution is an important part of the differentiation of excitable cells. Much is known about the distribution of ACh receptors (AChRs) on skeletal muscle cells (see review by Schuetze and Role, 1987). The receptors on mature, innervated cells are highly clustered, confined to the sites of synapses. This tight localization of receptors is under the control of the innervating neuron, beginning at the earliest stages of synaptogenesis, when ingrowing neurons can induce receptor aggregation at sites of contact, and being largely lost if the muscle is denervated (Schuetze and Role, 1987).

Relatively little is known about the subcellular localization of receptors on neurons of the CNS. For example, it is not known whether the distribution of receptors on the surfaces of CNS neurons changes during development. It has been shown that receptors for glycine, a mediator of synaptic inhibition in the spinal cord (Aprison and Daly, 1978; Young and Macdonald, 1983), are clustered on the surfaces of motoneurons in the adult rat spinal cord (Triller et al., 1985; van den Pol and Gorcz, 1988) and on other types of neurons in situ (Altschuler et al., 1986; Triller et al., 1991; Seitanidou et al., 1992). In each case, it appears that the glycine receptors (GlyRs) are localized to synapses, identified by the presence of presynaptic terminals, similar to the localization of AChRs at neuromuscular synapses, and Seitanidou et al. (1992) recently provided evidence that the distribution of GlyRs on CNS neurons may be controlled by innervating neurons. It is not known, though, how a tight localization of GlyRs comes about during development. Is there an early developmental stage at which GlyRs are more diffusely distributed than in the adult, as is the case for AChRs on developing muscle cells, or are GlyRs localized in clusters from the earliest stages of expression?

Srinivasan et al. (1990) recently examined the distribution of GlyRs on living rat spinal cord neurons in culture using a fluorescent derivative of the glycine antagonist strychnine to label GlyRs. They found that GlyRs typically were spread fairly uniformly over large areas of the neuronal surface, with an apparently continuous sheet of GlyRs sometimes covering half of a soma. This pattern was quite different from the tight clusters of 
GlyRs that Triller et al. (1985) observed on adult rat motoneurons in situ, and differed also from the nonuniform distributions of GlyRs and other receptors that have been described on CNS neurons in culture (Ransom et al., 1977; Barker et al., 1982; Macdonald et al., 1982, 1983; O'Brien and Fischbach, 1986; Trussell et al., 1988; Bekkers and Stevens, 1989; Clendening and Hume, 1990; Jones and Baughman, 1991). Their results suggested that the formation of clusters is not a requisite part of GlyR expression, but possible developmental changes in GlyR distribution were not examined.

Recent studies by Betz and colleagues (reviewed by Betz, 1991) and by Akagi and Miledi (1988a,b, 1989) have demonstrated the cxistence of multiplc forms of GlyR in the rat spinal cord and have suggested that the cells of the spinal cord undergo a developmental change between different forms of GlyR. The form that predominates at the time of birth does not bind the antagonist strychnine with high affinity (Becker et al., 1988). Another form of GlyR, possibly the sole form expressed in the adult, does display high-affinity binding of strychnine. The latter form of GlyR has been termed "adult" by Becker et al. (1988) and here is referred to as adult-type or strychnine-binding GlyR. We have used two different probes for the adult-type GlyR, strychnine and anti-GlyR mAb $2 \mathrm{~b}$ (Pfeiffer et al., 1984; Becker et al., 1988), to study the number and distribution of adult-type GlyRs on embryonic rat spinal cord neurons developing in vitro. We have found that such GlyRs are expressed by these neurons only after several days in culture, and that clusters of adult-type GlyRs in "mature" cultures are common, even at very early stages of expression. Our results also suggest that at lcast some of the adult-type GlyRs on some neurons may not be fully formed into clusters, and that this distribution may occur at the earliest stages of their expression.

Some of these results have appeared in abstract form (St. John and Stephens, 1990).

\section{Materials and Methods}

Tissue dissociation and cell culture. All experiments were begun with timed-pregnant Sprague-Dawley rats (Harlan). The day following an overnight mating was counted as embryonic day 0 (E0), and spinal cords were dissected and dissociated on E14. The methods for dissociation and culture of embryonic rat spinal cord neurons have been described elsewhere (Schaffner et al., 1987; St. John, 1991; St. John and Stephens, 1992). Dissociated cells were plated on monolayers of astrocytes, which were prepared from the cerebral cortices of E20 rat embryos. In some experiments, glial cell growth was retarded by fluorodeoxyuridine (10 $\mu \mathrm{M}$ ) added to the cultures for 2-3 d. Otherwise, culture media were changed every $3-4 \mathrm{~d}$.

For radioligand binding assays, cells were plated in 24-well microwell plates at $2 \times 10^{s}$ cells per well. For microscopy, neurons werc plated at densities of $5-20 \times 10^{4}$ cells per dish in specially constructed $35 \mathrm{~mm}$ culture dishes similar to those described by Hawrot and Patterson (1979). To construct these dishes, a hole approximately $8 \mathrm{~mm}$ in diameter was drilled through the bottom of a dish and covered from below by a glass coverslip sealed to the dish with Sylgard (Dow-Corning). This created a shallow well at the center of the dish, and neurons were plated in this well.

${ }^{3} H$-strychnine and ${ }^{125} I$-substance $P$ binding assays. Assays for GlyRs on neurons in vitro were performed by binding ${ }^{3} \mathrm{H}$-strychnine (New England Nuclear; specific activity, $22.8 \mathrm{Ci} / \mathrm{mmol}$; see Young and Snyder, 1973,1974 ) to live cells in culture. Assays normally were performed at room temperature, although comparable results were obtained at $4^{\circ} \mathrm{C}$. Cultures were rinsed with assay buffer [Hanks' Balanced Salts Solution (IIBSS) with $1 \mathrm{mg} / \mathrm{ml} \mathrm{BSA],} \mathrm{and} \mathrm{then} \mathrm{incubated} \mathrm{for} 60 \mathrm{~min}$ in assay buffer containing $5.6 \mathrm{nM}{ }^{3} \mathrm{H}$-strychnine; control cultures also contained $1 \mathrm{~mm}$ unlabeled strychnine (Sigma). Following this incubation, cultures were rinsed rapidly, then dissolved overnight in $1 \mathrm{NNaOH}$, and counted in a scintillation counter. All assays included triplicate samples.
Our preliminary experiments showed that cultured glial cells displayed specific ${ }^{3} \mathrm{H}$-strychnine binding (P. A. St. John and S. L. Stephens, unpublished observations). Since all spinal cord cultures include glial cells, ${ }^{3} \mathrm{H}$-strychnine binding to them had to be subtracted from binding to the whole culture to reveal the level of binding to neuronal GlyRs. Parallel ${ }^{3} \mathrm{H}$-strychnine binding assays were performed on cultures of neurons on glial cell feeder layers and cultures of glial cells with no added neurons. The difference between age-matched cultures was taken as the binding of ${ }^{3} \mathrm{H}$-strychnine to the neurons. Approximately $85 \%$ of the binding to neuronal or glial cultures could be displaced by unlabeled strychnine, and on neuronal cultures of $9 \mathrm{~d}$ or older, the specific binding to glial cells accounted for approximately $10 \%$ of all specific binding.

Assays for the binding of ${ }^{125}$ I-substance $P$ to living neurons were performed as described previously (St. John and Stephens, 1992).

Fluorescent labeling with Bodipy-strychnine. GlyRs were labeled for fluorescence microscopy with a fluorescent derivative of strychnine called Bodipy-strychnine (Srinivasan et al., 1990); Bodipy has spectra similar to fluorescein isothiocyanate (FITC) and can be visualized through FITC fluorescence filters. Bodipy-strychnine was diluted to $50 \mathrm{~nm}$ in HBSS and applied to live cultures for $30-60 \mathrm{~min}$ at room temp or $4^{\circ} \mathrm{C}$; control samples also contained $5 \mu \mathrm{M}$ unlabeled strychnine. Cultures normally were viewed in the continued presence of Bodipy-strychnine without rinsing, although in a few cases cells were rinsed with HBSS and viewed immediately afterward. Samples were viewed through a $100 \times$, N.A. 1.3 oil immersion fluorescence objective on an inverted microscope equipped with phase-contrast optics (Nikon Diaphot). Samples were photographed with Kodak Ektachrome P800/1600 or TMAX 3200 film.

Labeling with anti-GlyR antibody. Adult-type GlyRs were labeled on neurons in culture with $\mathrm{mAb} 2 \mathrm{~b}$, a monoclonal antibody raised against the affinity-purified GlyR from the rat spinal cord (Pfeiffer et al., 1984) that has been shown to recognize specifically the adult isoform of the a subunit of the GlyR (Becker et al., 1988). In experiments to quantify relative numbers of GlyRs, living neurons in culture were exposed to primary antibody ( 60 min at room temperature), followed by ${ }^{125}$ I-labeled goat anti-mouse secondary antibody (New England Nuclear; $60 \mathrm{~min}$ at room temperature); the cells were then dissolved, and the binding was quantified by gamma counting. In experiments to localize GlyRs by microscopy, living neurons in culture were exposed to primary antibody (60 min at room temperature, unless otherwise indicated), followed by FITC-conjugated secondary antibody (Jackson ImmunoResearch, 60 min at room temperature), and then were observed by fluorescence microscopy.

\section{Results}

Development of adult-type GlyRs in vitro

Becker et al. (1988) have shown that in the rat spinal cord, only the "adult" form of the GlyR exhibits high-affinity binding of strychnine. In the experiments reported here, GlyRs of this type are referred to alternately as adult-type or strychnine-binding GlyRs. The development of adult-type GlyRs was assayed first by the binding of ${ }^{3} \mathrm{H}$-strychnine to living spinal cord neurons in culture. This binding was found to be was time dependent (Fig. 1A), reaching a plateau level within $60 \mathrm{~min}$. Approximately $85 \%$ of the binding could be displaced by $1 \mu \mathrm{M}$ unlabeled strychnine. The binding of ${ }^{3} \mathrm{H}$-strychnine to living cultures was reversible (Fig. $1 B$ ), as expected for binding to cell-surface receptors, and the dissociation appeared to be a first-order process. It appeared likely that the reversible, displaceable ${ }^{3} \mathrm{H}$-strychnine binding sites revealed in these assays were adult-type GlyRs. Further support for this conclusion came from assays of the binding of anti-GlyR antibody to these cultures (below). The expression of adult-type GlyRs on the neurons in these cultures was consistent both with the previous observations of Hoch et al. (1989) and with more recent electrophysiological observations (Withers et al., 1992).

In order to monitor the in vitro development of adult-type GlyRs, ${ }^{3} \mathrm{H}$-strychnine binding assays were performed on cultures of spinal cord neurons after different lengths of time in culture. Membrane preparations from the rat spinal cord at E14, 

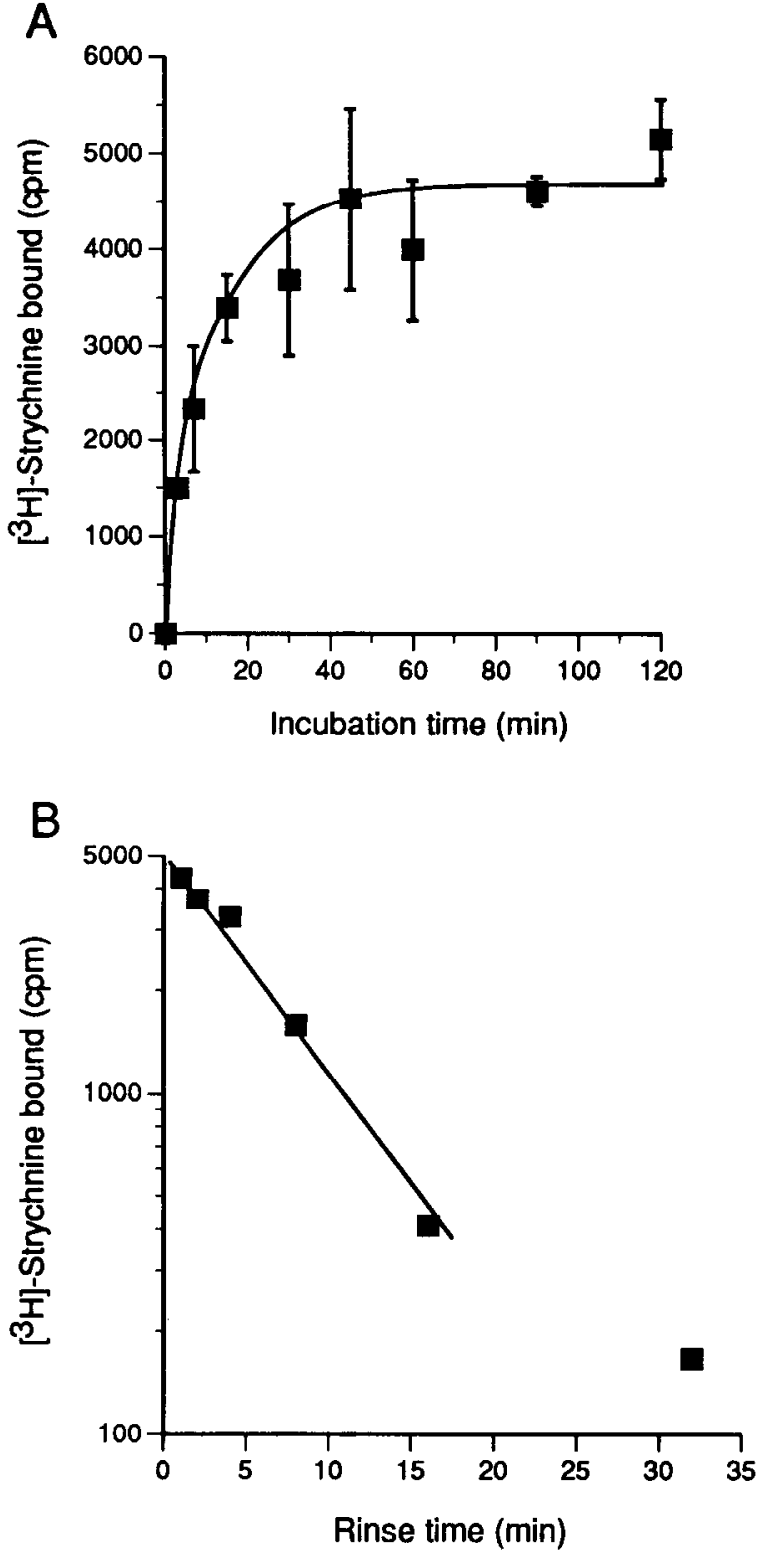

Figure 1. Association and dissociation of ${ }^{3} \mathrm{H}$-strychnine on cultured spinal cord cells. $A$, Cultures were exposed to ${ }^{3} \mathrm{H}$-strychnine for the times indicated, and then rinsed rapidly and prepared for scintillation counting as described in Materials and Methods. $B$, Cultures were incubated in ${ }^{3} \mathrm{H}$-strychnine for $60 \mathrm{~min}$, rinsed rapidly, and held in buffer for the times indicated, and then rinsed again and prepared for scintillation counting. Values are the means $( \pm \mathrm{SD})$ of triplicate samples from one experiment. The curves are drawn by eye.

the age used to prepare cultures, displayed no specific binding of ${ }^{3} \mathrm{H}$-strychnine (not shown). Cells dissociated at E14 and placed in culture attached to the substrate and began to extend processes within $24 \mathrm{hr}$. After several days, such neurons had formed extensive networks of processes. During these first days in culture, however, no ${ }^{3} \mathrm{H}$-strychnine binding was observed (Fig. $2 A$ ). In some experiments, neurons began to display ${ }^{3} \mathrm{H}$-strychnine binding after $4 \mathrm{~d}$ in culture (experiment 2 in Fig. $2 A$ ), but in most experiments, no binding was detected until neurons had been in culture for 6-7 $\mathrm{d}$ (experiment 1 in Fig. $2 A$ ). In all five cxperiments performed, however, there was an abrupt rise in the level of ${ }^{3} \mathrm{H}$-strychnine binding after neurons had been in
A

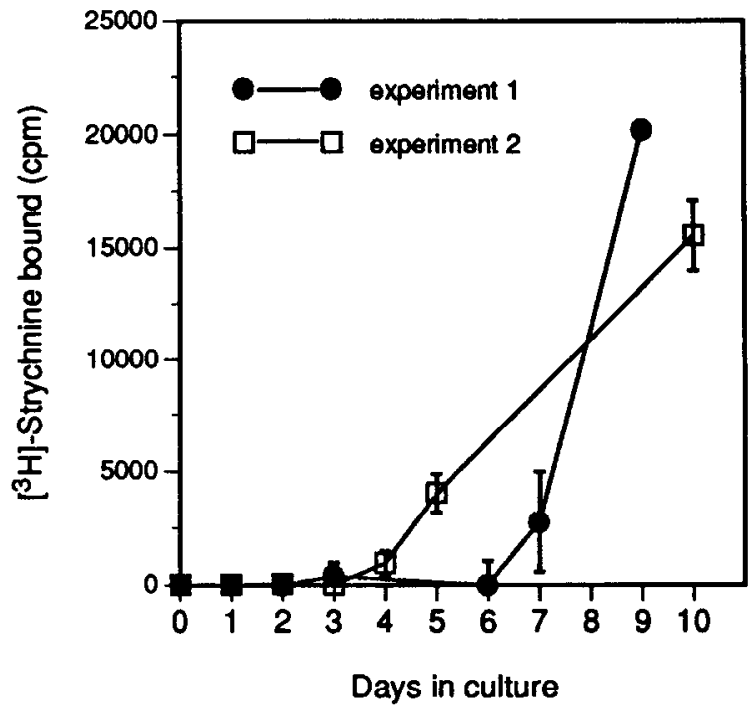

B

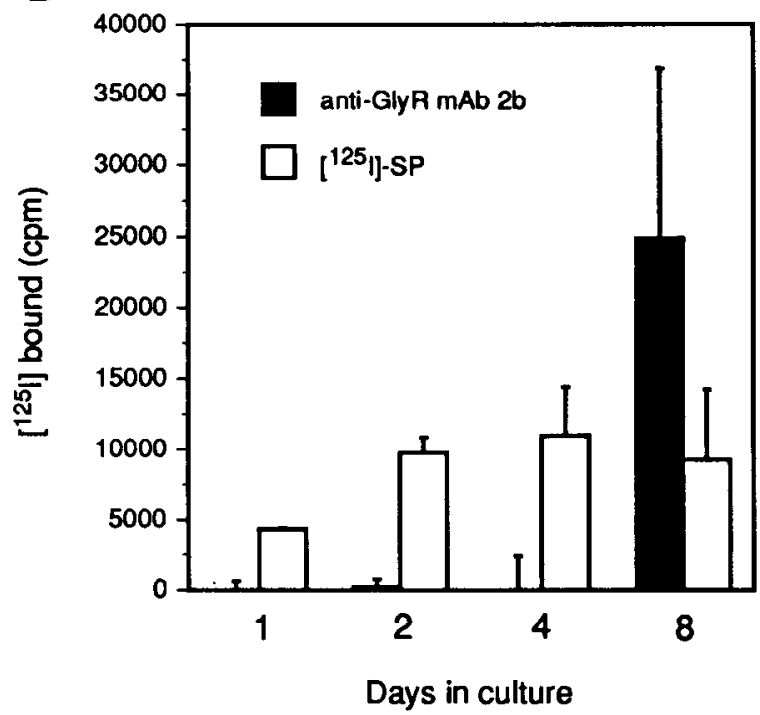

Figure 2. Development of adult-type GlyRs on spinal cord neurons in vitro. $A$, Binding assays using ${ }^{3} \mathrm{H}$-strychnine were performed on sibling cultures from a single plating after the indicated times in vitro. Specific binding to glial cells, accounting for approximately $10 \%$ of all specific binding (see Materials and Methods), has been subtracted. Values are the means $( \pm S D)$ of triplicate samples. The two experiments shown were performed on separate platings of cells prepared on different days, and their results are typical of those from five scparate experiments. $B$, Binding assays using either anti-GlyR $\mathrm{mAb} 2 \mathrm{~b}$ followed by ${ }^{125}$ I-secondary antibody (solid bars) or ${ }^{125}$ I-substance $\mathrm{P}$ (open bars) were performed on sibling cultures from a single plating after the indicated times in vitro. Values are the means $( \pm \mathrm{SD})$ of triplicate samples in a single experiment.

culture for 5-7 d. Thus, adult-type GlyRs were not detected before $4 \mathrm{~d}$ in vitro, and the expression of such receptors appeared to increase abruptly after neurons had been in culture for 5-7 d.

The time course of development of adult-type GlyRs on these neurons was also followed by assays of the binding of a specific anti-GlyR antibody to cultures of different ages. The antibody used in these experiments, mAb $2 b$ (Pfeiffer et al., 1984), has been shown to recognize only the adult form of the $\alpha$ subunit of the GlyR in the rat spinal cord (Becker et al., 1988). In the 


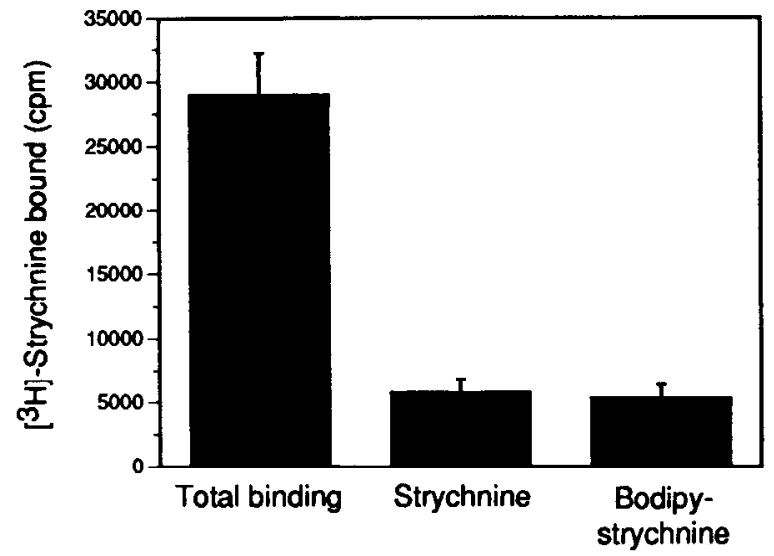

Figure 3. Competition of ${ }^{3} \mathrm{H}$-strychnine binding with strychnine and Bodipy-strychnine. Cultures were exposed to $5.6 \mathrm{nM}{ }^{3} \mathrm{H}$-strychnine alone or in the presence of $100 \mathrm{nM}$ Bodipy-strychnine or $1 \mu \mathrm{M}$ strychnine, and then were rinsed rapidly and prepared for scintillation counting.

present experiments, binding of this antibody was performed on living cultures. No specific binding was observed on neurons that had been in culture for $4 \mathrm{~d}$ or less (Fig. $2 B$ ). At $8 \mathrm{~d}$ in vitro, however, significant binding was detected. The same cultures did display specific binding sites for ${ }^{125} \mathrm{I}$-substance $\mathrm{P}$ beginning at $1 \mathrm{~d}$ in culture, as expected from previous experiments (St. John and Stephens, 1992), showing that the neurons in these cultures were capable of expressing receptors even very early. These results, using a second probe for the GlyR protein, confirmed that there was a delay of several days in vitro before spinal cord neurons began to express adult-type GlyRs.

\section{Cellular distributions of adult-type GlyRs}

To investigate possible heterogeneity among neurons in the time course of GlyR development, GlyRs on cultured neurons were labeled with a fluorescent derivative of strychnine, Bodipystrychnine (Srinivasan et al., 1990). This derivatized, fluorescent strychnine was tested for the specificity of its binding to the GlyR by competition in a ${ }^{3} \mathrm{H}$-strychnine binding assay. Bodipystrychnine at $100 \mathrm{~nm}$ displaced the binding of $5.6 \mathrm{~nm}^{3} \mathrm{H}$-strychnine as completely as $1 \mu \mathrm{M}$ unlabeled strychnine did (Fig. 3). This observation agreed with the results of Srinivasan et al. (1990), who previously showed that Bodipy-strychnine had virtually the same $K_{i}$ as underivatized strychnine, approximately $14 \mathrm{nM}$, in displacing the binding of ${ }^{3} \mathrm{H}$-strychnine to membrane fragments from bovine spinal cord.

Bodipy-strychnine was applied to neurons at a concentration of $50 \mathrm{~nm}$ for $60 \mathrm{~min}$, long enough for the level of specific labeling to reach a plateau (Srinivasan et al., 1990; St. John and Stephens, unpublished observations; compare Fig. 1). On neurons that had been in culture for less than 5-7 d, there were few or no neurons detectably labeled. Specific labeling first could be seen on neurons after 5-7 d in culture. The proportion of neurons in the culture that displayed visible labeling rose rapidly, and within 2-3 d after the first appearance of labeling, $80 \%$ of the neurons in the culture were labeled (Fig. 4). Specific labeling of glial cells could not be detected with this method at any age examined. Thus, a large majority of spinal cord neurons came to express adult-type GlyRs in culture, and the timing of the initial expression was rather synchronized among the different neurons.

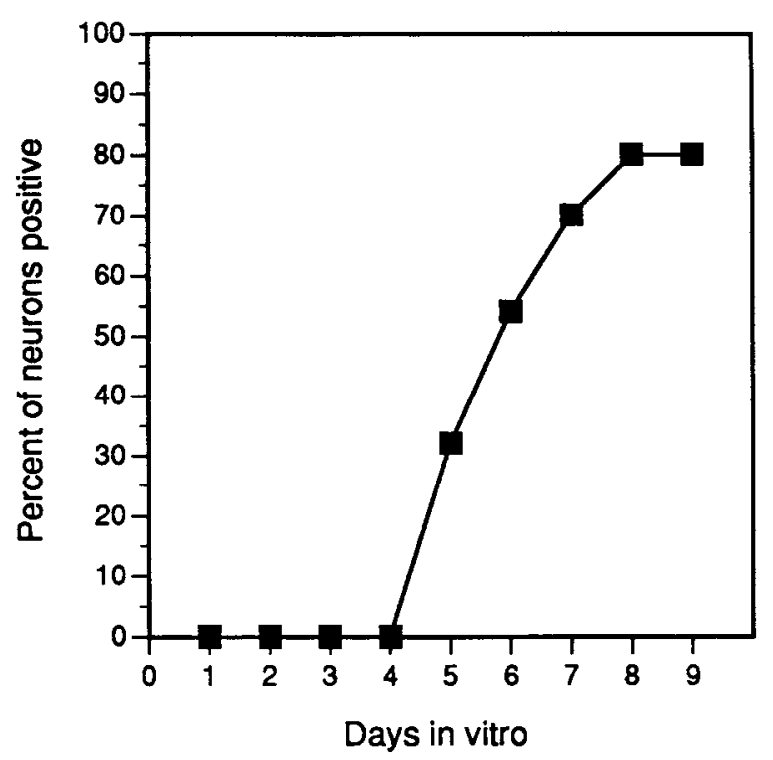

Figure 4. Development of expression of adult-type GlyRs by spinal cord neurons in vitro. At the indicated ages in vitro, sibling cultures from a single plating of neurons were labeled with Bodipy-strychnine and examined by fluorescence microscopy. At each age, at least 200 neurons, identified as neurons on the basis of morphology and randomly chosen, were scored for the presence of visible, specific labeling. Values are the proportion of neurons in single cultures that were labeled at each age.

\section{Subcellular distributions of adult-type GlyRs}

The subcellular distribution of adult-type GlyRs on neurons was mapped in separate experiments using two different labels for the receptor. One was the anti-GlyR mAb $2 b$, which was used to label neurons that had been in culture for $10 \mathrm{~d}$ or more. Incubation of living cultures in $\mathrm{mAb} 2 \mathrm{~b}$, followed by fluorescent secondary antibody, resulted in the specitic labeling of the large majority of neurons in the cultures. The proportion of labeled neurons was not quantified, but it appeared to be similar to that obtained with Bodipy-strychnine (above). In each case, labeling by the antibody was confined to the cell surface, as expected for an antibody binding to receptors on living neurons. No specific labeling was observed on glial cells.

The distribution over the surfaces of neurons of the GlyRlike material labeled by $\mathrm{mAb} 2 \mathrm{~b}$ was distinctly nonuniform. Figure 5 shows this labeling on neurons that had been in culture for 3 weeks. The GlyR-like material was localized to focal clusters that were present on both the cell bodies and the neurites of the neurons. Since a whole-antibody preparation was used for these experiments, it seemed possible that the bivalent antibodies had induced clustering of the GlyR-like material. This possibility was examined by performing labeling on living neurons at $4^{\circ} \mathrm{C}$ and on neurons that had been fixed briefly before labeling. In each case, the labeling was patchy and nonuniform (not shown), indicating that this pattern was not induced by the labeling procedure, but instead reflected the distribution of the GlyR-like material on the surfaces of living neurons in these cultures.

In order to verify that the distribution of GlyR-like material labeled by $\mathrm{mAb} 2 \mathrm{~b}$ was in fact the distribution of adult-type GlyRs, separate labeling experiments were performed in which GlyRs were labeled with Bodipy-strychnine. This approach took advantage of the previous finding (Becker et al., 1988) that only 

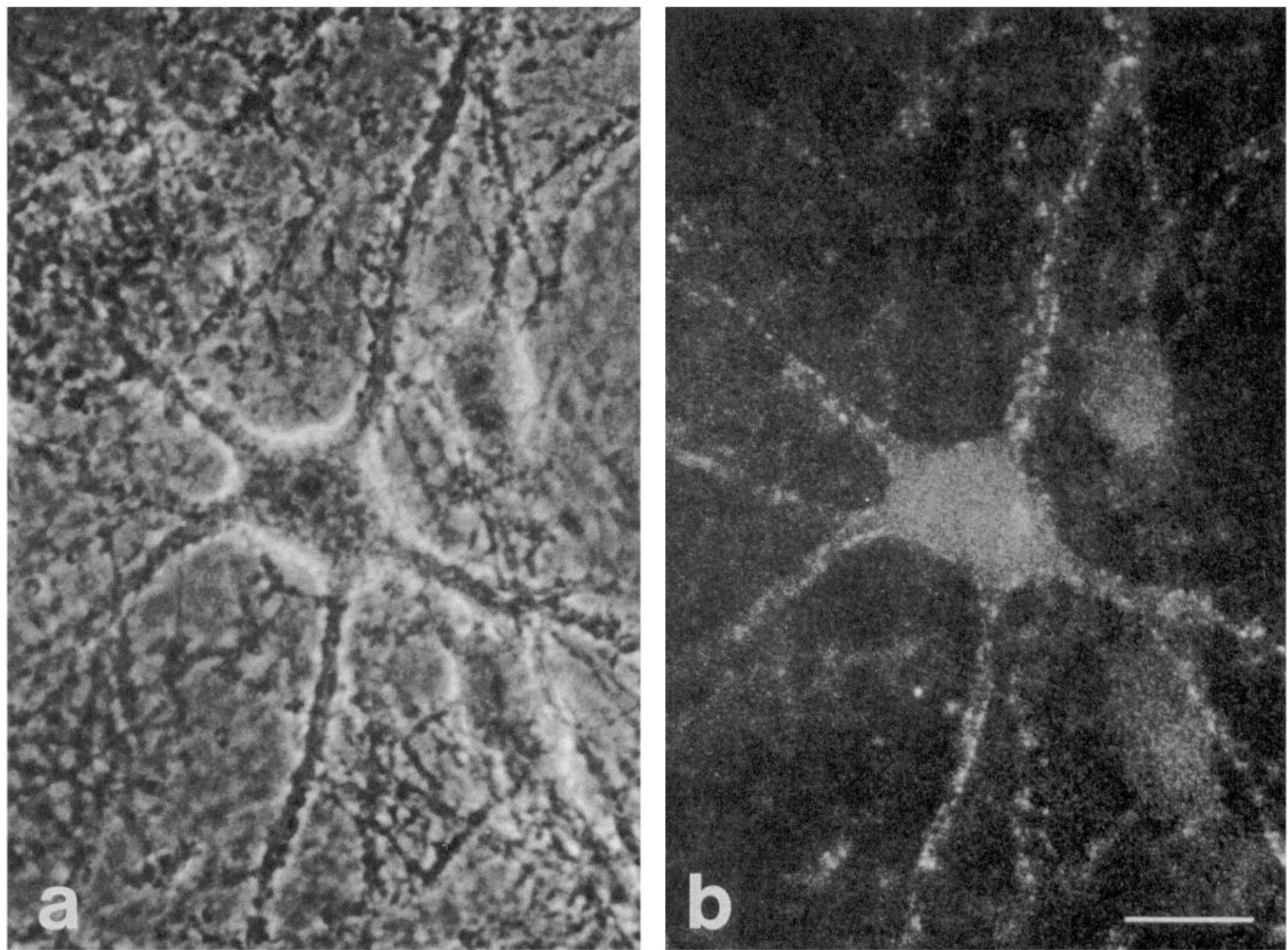

Figure 5. Distribution of immunologically identified adult-type GlyRs on spinal cord neurons in culture. Neurons that had been in culture for 2 weeks were labeled, without prior fixation, using anti-GlyR mAb $2 \mathrm{~b}$ and a fluorescent secondary antibody. This figure shows the same field in phase-contrast $(a)$ and fluorescence $(b)$. Note the presence of spots of labeling scattered over both the cell body and the processes of the prominent neuron. Scale bar, $10 \mu \mathrm{m}$.

the adult-type GlyRs of the rat spinal cord bind strychnine with high affinity. In these experiments, the largest portion of the labeling by Bodipy-strychnine was at or near the cell surface (Fig. 6), and only limited labeling was seen deeper in cells. Most or all of the cell-surface labeling was due to specific binding, since it was displaced by $1 \mu \mathrm{M}$ unlabeled strychnine (Fig. 6), while little of the deeper intracellular fluorescence was judged to be specific, since it was not displaced by unlabeled strychnine. In light of the results with $\mathrm{mAb} 2 \mathrm{~b}$ (above), we concluded that the specific labeling at the cell surface resulted from the binding of Bodipy-strychnine to adult-type GlyRs on the neuronal surface.

On neurons that had been in culture for $10 \mathrm{~d}$ or more, the pattern of labeling with Bodipy-strychnine was like that seen with $\mathrm{mAb} 2 \mathrm{~b}$ at comparable in vitro ages (above). Labeled GlyRs were localized to small, focal patches that were distributed over the cell bodies and neurites of the neurons (Fig. 6). The regions between these patches appeared to be unlabeled at these ages.

Clusters of GlyRs were also prominent on neurons that had been in culture for 5-7 d, that is, on neurons that had just begun to express adult-type GlyRs (see above). At these early stages, however, in addition to the clusters, many neurons showed evidence of GlyRs that were more diffusely dispersed over the neuronal surface (Fig. 7). This labeling could be seen most clearly as a rim of labeling around the perimeter of the cell body when the neuron was viewed at a focal plane through the center of the soma (e.g., Fig. $7 f$ ). As shown in Figure 7, this diffuse labeling was much dimmer than that in the patches. Even at early stages of adult-type GlyR expression, many neurons did not display visible diffuse labeling of this type, and no neurons were seen to have diffuse GlyRs without clusters. However, this type of diffuse labeling was commonly seen on neurons at 5-7 d in culture and was not seen on neurons that had been in culture for $10 \mathrm{~d}$ or longer.

\section{Discussion}

Development and cellular distribution of adult-type GlyRs These results describe the development and the distributions of adult-type, or strychnine-binding, GlyRs on rat spinal cord neurons developing in vitro. Binding assays showed that rat spinal cord neurons in culture express specific ${ }^{3} \mathrm{H}$-strychnine binding sites. The characteristics of the binding, taken with the work of 

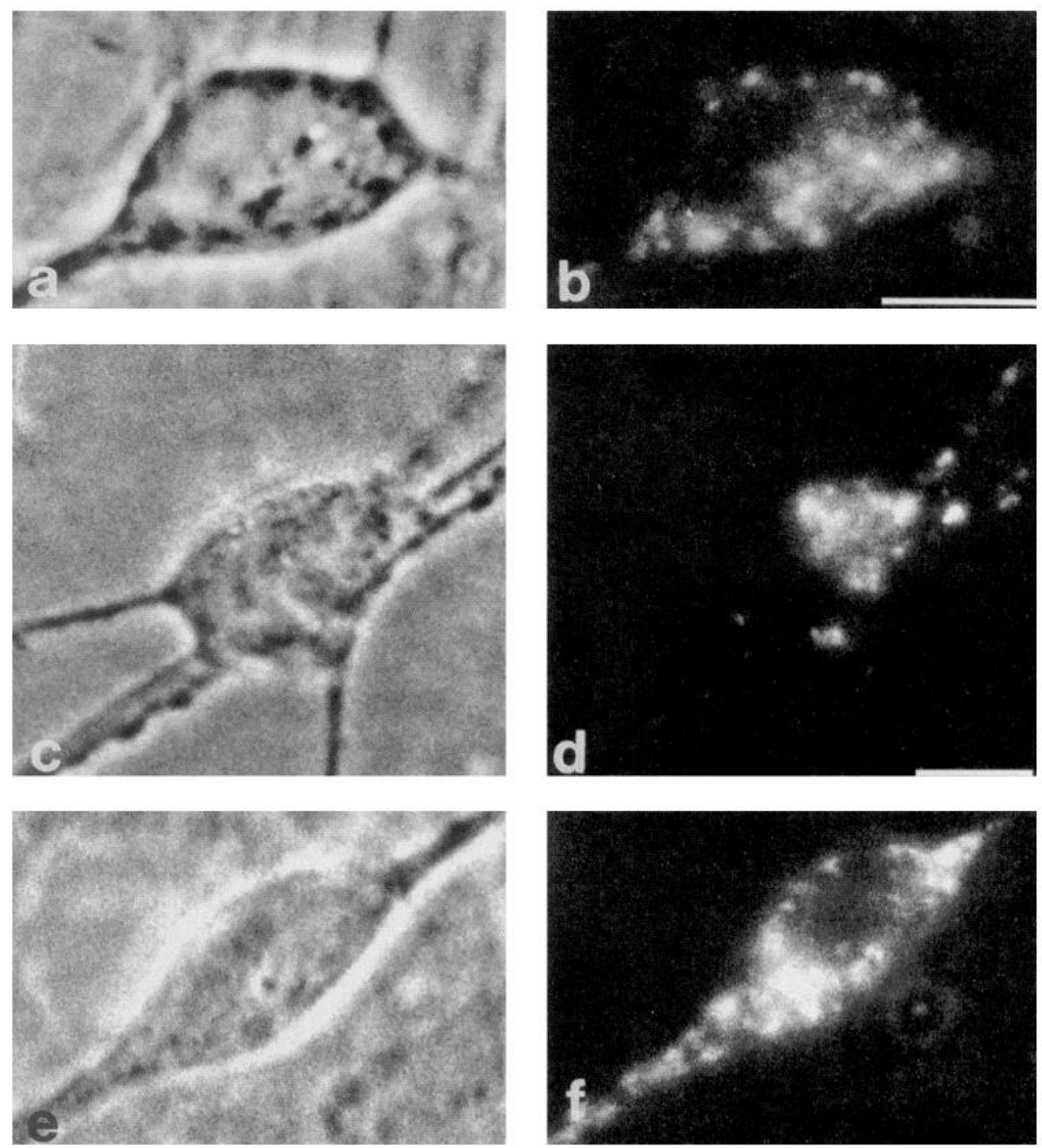

Figure 6. Bodipy-strychnine labeling of GlyRs on spinal cord neurons at 10 $\mathrm{d}$ or more in culture. Living spinal cord neurons in culture were equilibrated in 50 nм Bodipy-strychnine, and then were viewed without rinsing. This figure shows paired phase-contrast $(a, c, e, g)$ and fluorescence $(b, d, f, h)$ views of neurons that had been in culture for 2 weeks $(a-d)$ or $10 \mathrm{~d}(e-h)$. Note the presence of focal clusters of labeling on neurons $a-f$, and the absence of labeling on a control neuron $(g, h)$ coincubated with $5 \mu \mathrm{M}$ unlabeled strychnine. Scale bars, $10 \mu \mathrm{m}$; bar in $d$ applies to $c-h$
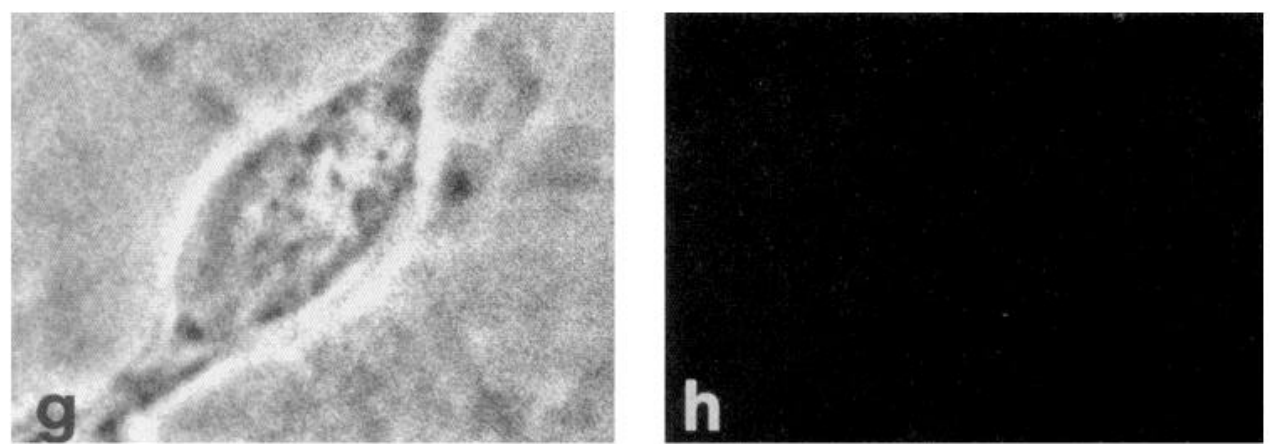

Betz and colleagues (e.g., Becker et al., 1988), suggest that these binding sites are adult-type GlyRs. This is confirmed by the specific binding to these cultured neurons of a second probe for the adult-type GlyR, mAb $2 \mathrm{~b}$ against the adult isoform of the GlyR $\alpha$ subunit (Pfeiffer et al., 1984; Becker et al., 1988). Adulttype GlyRs could not be detected in the rat spinal cord at E14, the age when cells were dissociated for culture. Once in culture, neurons showed other signs of differentiation, including expression of substance $P$ receptors, but did not express adulttype GlyRs for several days. Both ${ }^{3} \mathrm{H}$-strychnine binding assays and $\mathrm{mAb} 2 \mathrm{~b}$ binding assays showed that a dramatic increase in the level of adult-type GlyRs occurred at 5-7 d in culture. Betz and colleagues have suggested that spinal cord neurons undergo a switch in GlyR expression from a "neonatal" type present at the time of birth to the "adult," strychnine-binding type (Becker et al., 1988). Perhaps such a developmental change occurs in these cultures. Although the reason for the delay in expression of adult-type GlyRs is not clear, for our subsequent experiments, we took 5-7 d in vitro as the time of initial expression of adulttype GlyRs in these cultures. 

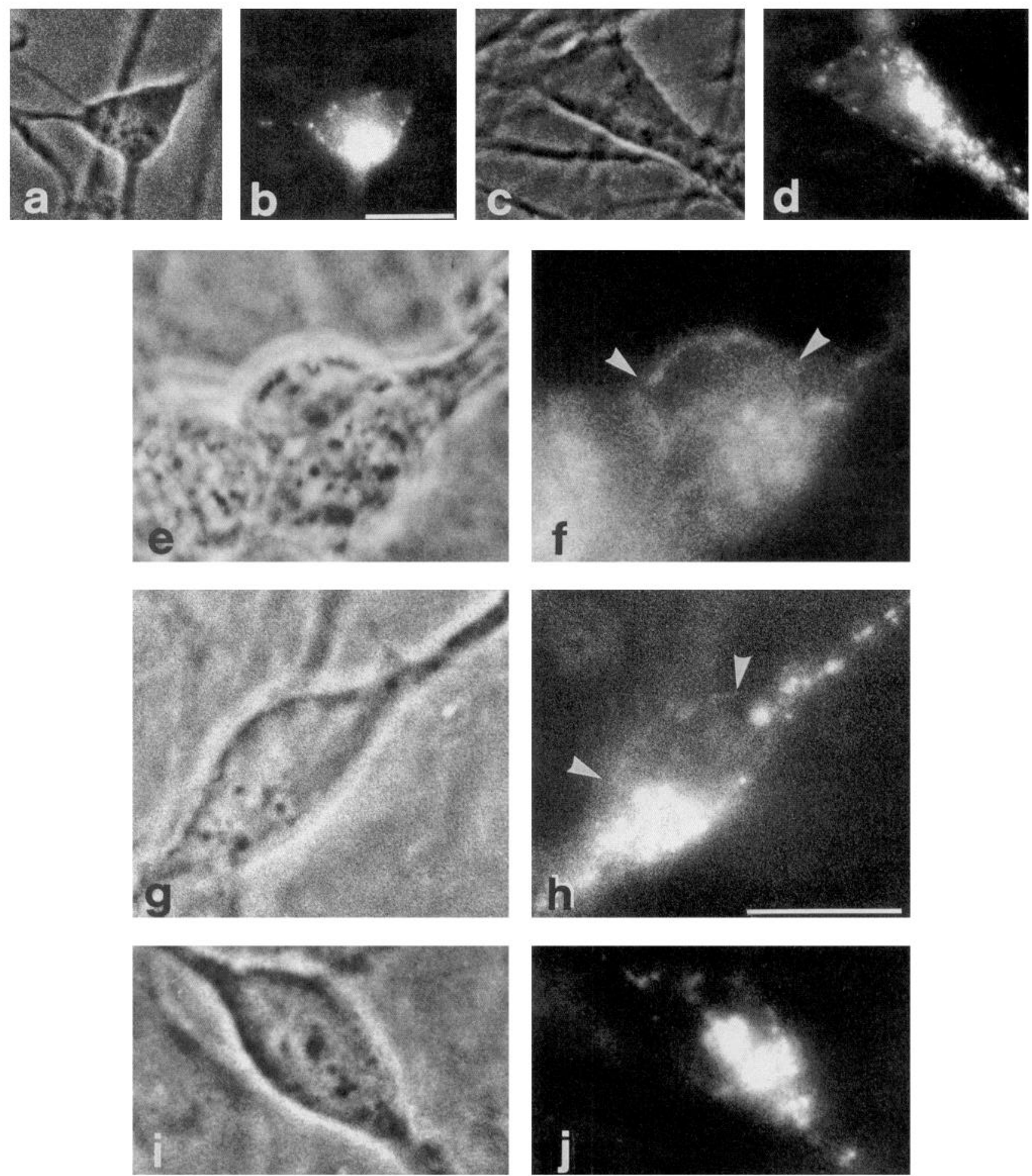

Figure 7. Bodipy-strychnine labeling of GlyRs on spinal cord neurons at 5-7 d in culture. Labeling was performed as for Figure 6. This figure shows paired phase-contrast $(a, c, e, g, i)$ and fluorescence $(b, d, f, h, j)$ views of neurons that had been in culture for $7 \mathrm{~d}(a-d)$ or $6 \mathrm{~d}(e-j)$. Note the presence of clusters of GlyRs in each case as well as the dimmer rim of labeling around the perimeters of certain neurons (particularly visible in $b, d, f, h$; arcs between arrowheads in $f$ and $h$ ). Scale bars, $10 \mu \mathrm{m}$; bar in $b$ applies to $a-d$, and bar in $h$ applies to $e-j$.

The cellular distribution of GlyRs was examined using a fluorescent derivative of strychnine and fluorescence microscopy. Little if any labeling of neurons could be detected before $5-7 \mathrm{~d}$ in vitro, in good agreement with the results of the ${ }^{3} \mathrm{H}$-strychnine and the mAb $2 \mathrm{~b}$ binding assays. Beginning at $5-7 \mathrm{~d}$ in vitro, labeling became detectable and increased abruptly, so that after $8 \mathrm{~d}$ in vitro, $80 \%$ of all neurons were visibly labeled. The conclusion that a high proportion of neurons in these cultures express GlyRs is consistent with the conclusions of other investigators who used electrophysiological methods to study 
comparable cultures of rat, mouse, and chick neurons (Nelson et al., 1977; Ransom et al., 1977; Jackson et al., 1982; O'Brien and Fischbach, 1986; Smith et al., 1989; Clendening and Hume, 1990).

\section{Subcellular distribution of adult-type GlyRs}

Fluorescence microscopy using both Bodipy-strychnine and $\mathrm{mAb}$ $2 b$ revealed two significant observations about the subcellular distributions of adult-type GlyRs on these cultured neurons. First, on neurons that had been in culture for $10 \mathrm{~d}$ or more, receptors were localized to discrete clusters, or aggregates, on the neuronal surface. Little or no diffuse labeling was visible between clusters. The clusters were observed on living neurons with both the bivalent mAb $2 \mathrm{~b}$ and the monovalent Bodipystrychnine, they were observed when labeling was performed at low temperature, and with mAb $2 b$, they were observed on neurons that had been fixed before labeling. These observations lead to the conclusion that adult-type GlyRs on living neurons in these cultures are localized to focal clusters.

The clusters of GlyRs on these spinal cord neurons in culture qualitatively resemble the clusters of GlyRs that have been observed on rat spinal cord and other neurons in situ (Triller et al., 1985; Altschuler et al., 1986; van den Pol and Gorcz, 1988; Triller et al., 1.991; Seitanidou et al., 1992). Moreover, the clusters of cell-surface GlyRs observed here by microscopy are reminiscent of the nonuniform distributions of sensitivity to various amino acid neurotransmitters that others have discerned on cultured neurons using electrophysiological methods (Ransom et al., 1977; Barker et al., 1982; Macdonald et al., 1982, 1983; O'Brien and Fischbach, 1986; Trussell et al., 1988; Bekkers and Stevens, 1989; Clendening and Hume, 1990; Jones and Baughman, 1991).

The pattern described here, with many small, focally localized clusters of GlyRs on neurons, contrasts with that described by Srinivasan et al. (1990). Those authors reported that the adulttype GlyRs on rat spinal cord neurons that had been in culture for 3 weeks were spread rather uniformly over large areas on the neuronal surface, with single patches of GlyRs sometimes extending over half a cell body. This apparent discrepancy could be due to the difference in how the labeling of GlyRs was observed and recorded. Srinivasan et al. (1990) obtained images of labeling with a photon-counting video camera. The authors noted that the dynamic range of the camera, and therefore the ability to discriminate labeling of different intensities, was limited. The results presented here were recorded on photographic film, with a wider dynamic range and higher spatial resolution. These characteristics might have improved our ability to record small patches of bright labeling interspersed with lightly labeled or unlabeled regions.

The results presented here also suggest that the distribution of adult-type GlyRs on a neuron may change during the first few days in vitro that the neuron expresses those receptors. The results of the ${ }^{3} \mathrm{H}$-strychnine binding and the Bodipy-strychnine labeling experiments showed that neurons that had been in culture for 5-7 d were in the early stages of expression of adulttype GlyRs. On neurons at this stage, clusters of GlyRs were prominent, as on older neurons. Indeed, at no stage were any neurons found on which clusters of GlyRs were absent. But in contrast to neurons several days older, many neurons at 5-7 d showed evidence of diffuse labeling in addition to the clusters.

The results presented here provide direct evidence, using two independent probes, that adult-type GlyRs can form focal clus- ters on spinal cord neurons in vitro that resemble those observed on neurons in situ. Indeed, focal clusters constituted the characteristic pattern of GlyR distribution in the present experiments.

These results also provide, to our knowledge, the first microscopic evidence on possible changes in the distribution of ncurotransmitter receptors during the development of CNS neurons. There are two points to be made here. First, many adulttype GlyRs were collected in clusters even at the earliest stages of their expression. Second, there may be an early developmental stage at which some unclustered receptors are present, as well.

It is not clear from these experinents whether clustering of adult-type GlyRs is induced during development, as is the case for AChRs during the development and innervation of skeletal muscle cells. In the case of AChRs, clustering of receptors is induced by the presynaptic neuron. The significance of the location of the GlyR clusters we have seen on neurons in vitro is not clear. Since GlyR clusters can be localized to synapses in situ (Triller et al., 1985, 1987; van den Pol and Gorcz, 1988) and since it has been shown that glutamate receptors are localized to synapses on rat hippocampal neurons (Bekkers and Stevens, 1989) and neocortical neurons (Jones and Baughman, 1991) in culture, it is reasonable to speculate that the GlyR clusters described here may be located at synapses, possibly glycinemediated ones, between the neurons in these cultures. If that is the case, the difference between the distinct clusters of GlyRs described here and the lack of clusters described by Srinivasan et al. (1990) could result from differences in the abundance of synapses in the cultures in the two laboratories. Additional experiments will be needed to test this possibility.

\section{References}

Akagi H, Miledi R (1988a) Expression of glycine and other amino acid receptors by rat spinal cord mRNA in Xenopus oocytes. Neurosci Lett 95:262-268.

Akagi H, Miledi R (1988b) Heterogeneity of glycine receptors and their messenger RNAs in rat brain and spinal cord. Science $242: 270$ 273.

Akagi H, Patton DE, Miledi R (1989) Discrimination of heterogeneous mRNAs encoding strychnine-sensitive glycine receptors in Xenopus oocytes by antisense oligonucleotides. Proc Natl Acad Sci USA 86: 8103-8107.

Altschuler RA, Betz H, Parakkal MH, Reeks KA, Wenthold RJ (1986) Identification of glycinergic synapses in the cochlear nucleus through immunocytochemical localization of the postsynaptic receptor. Brain Res 369:316-320.

Aprison MH, Daly EC (1978) Biochemical aspects of transmission at inhibitory synapses: the role of glycine. Adv Neurochem 3:203-294

Barker JL, McBurney RN, Macdonald JF (1982) Fluctuation analysis of neutral amino acid responses in cultured mouse spinal neurones. J Physiol (Lond) 322:365-387.

Becker C-M, Hoch W, Betz H (1988) Glycine receptor heterogeneity in rat spinal cord during postnatal development. EMBO J 7:37173726.

Bekkers JM, Stevens CF (1989) NMDA and non-NMDA receptors are co-localized at individual excitatory synapses in cultured rat hippocampus. Nature $341: 230-233$.

Betz H (1991) Glycine receptors: heterogeneous and widespread in the mammalian brain. Trends Neurosci 14:458-461.

Clendening B, Hume RI (1990) Expression of multiple neurotransmitter receptors by sympathetic preganglionic neurons in vitro. J Neurosci 10:3977-3991.

Hawrot E, Patterson PH (1979) Long-term culture of dissociated sympathetic neurons. Methods Enzymol 58:574-583.

Hoch W, Betz H, Becker C-M (1989) Primary cultures of mouse spinal cord express the neonatal isoform of the inhibitory glycine receptor. Neuron 3:339-348. 
Jackson MB, Lecar H, Brenneman DE, Fitzgerald S, Nelson PG (1982) Electrical development in spinal cord cell culture. J Neurosci 2:10521061.

Jones KA, Baughman RW (1991) Both NMDA and non-NMDA subtypes of glutamate receptors are concentrated at synapses on cerebral cortical neurons in culture. Neuron 7:593-603.

Macdonald RL, Moonen G, Neale EA, Nelson PG (1982) Cerebellar macroneurons in microexplant cell culture. Postsynaptic amino acid pharmacology. Dev Brain Res 5:75-88.

Macdonald RL, Pun RY, Neale EA, Nelson PG (1983) Synaptic interactions between mammalian central neurons in cell culture. I. Reversal potential for excitatory postsynaptic potentials. J Neurophysiol 49:1428-1441.

Nelson PG, Ransom BR, Henkart M, Bullock PN (1977) Mouse spinal cord in cell culture. IV. Modulation of inhibitory synaptic function. J Neurophysiol 40:1178-1187.

O'Brien RJ, Fischbach GD (1986) Modulation of embryonic chick motoneuron glutamate sensitivity by interneurons and agonists. J Neurosci 6:3290-3296.

Pfeiffer F, Simler R, Grenningloh G, Betz H (1984) Monoclonal antibodies and peptides mapping reveal structural similarities between the subunits of the glycine receptors of rat spinal cord. Proc Natl Acad Sci USA 81:7224-7227.

Ransom BR, Bullock PN, Nelson PG (1977) Mouse spinal cord in cell culture. III. Neuronal chemosensitivity and its relationship to synaptic activity. J Neurophysiol 40:1163-1177.

Schaffner AE, St. John PA, Barker JL (1987) Fluorescence-activated cell sorting of embryonic mouse and rat motoneurons and their longterm survival in vitro. J Neurosci 7:3088-3104.

Schuetze SM, Role LW (1987) Developmental regulation of nicotinic acetylcholine receptors. Annu Rev Neurosci 10:403-457.

Seitanidou T, Nicola M-A, Triller A, Korn H (1992) Partial glycinergic denervation induces transient changes in the distribution of a glycine receptor-associated protein in a central neuron. J Neurosci 12:116131.

Smith SM, Zorec R, McBurney RN (1989) Conductance states activated by glycine and GABA in rat cultured spinal neurones. J Membr Biol 108:45-52.
Srinivasan Y, Guzikowski AP, Haugland RP, Angelides KJ (1990) Distribution and lateral mobility of glycine receptors on cultured spinal cord neurons. J Neurosci 10:985-995.

St. John PA (1991) Toxicity of "DiI" for embryonic rat motoneurons and sensory neurons in vitro. Life Sci 49:2013-2021.

St. John PA, Stevens SL (1990) Glycine receptors on rat motoneurons developing in vitro. Soc Neurosci Abstr 16:42.

St. John PA, Stevens SL (1992) Development of substance P receptors on rat motoneurons in vitro. Dev Biol 151:154-165.

Triller A, Cluzeaud F, Pfeiffer P, Betz H, Korn H (1985) Distribution of glycine receptors at central synapses: an immunoelectron microscopy study. J Cell Biol 101:683-688.

Triller A, Cluzeaud F, Korn H (1987) $\gamma$-Aminobutyric acid-containing terminals can be apposed to glycine receptors at central synapses. J Cell Biol 104:947-956.

Triller A, Seitanidou T, Franksson O, Korn H (1991) Use of confocal microscope for the cellular analysis of the glycine synaptic receptor. J Receptor Res 11:347-357.

Trussell LO, Thio LL, Zorumski CF, Fischbach GD (1988) Rapid desensitization of glutamate receptors in vertebrate central neurons. Proc Natl Acad Sci USA 85:4562-4566.

van den Pol A, Gorcs T (1988) Glycine and glycine receptor immunoreactivity in brain and spinal cord. J Neurosci 8:472-492.

Withers MD, Levine RB, St. John PA (1992) Strychnine sensitivity of glycine responses of embryonic rat spinal cord neurons in culture. Soc Neurosci Abstr 18:610.

Young AB, Macdonald RL (1983) Glycine as a spinal cord neurotransmitter. In: Handbook of the spinal cord, Vol 1 (Davidoff RA, cd), pp 1-43. Ncw York: Dekkcr.

Young AB, Snyder SH (1973) Strychnine binding associated with glycine receptors of the central nervous system. Proc Natl Acad Sci USA 70:2832-2836.

Young AB, Snyder SH (1974) Strychnine binding in rat spinal cord membranes associated with the synaptic glycine receptor: cooperativity of glycine interactions. Mol Pharmacol 10:790-800. 